\title{
Frequency of Blindness Due to Zygomatic Fracture in Hazrat Fatemeh Hospital
}

\author{
Nour-Ahmad Latifi' ${ }^{1}$, Hamid Karimi1 ${ }^{*}$, Fezzeh Elyasinia ${ }^{2}$ \\ ${ }^{1}$ Department of Plastic Surgery, Faculty of Medicine, Iran University of Medical Sciences, Tehran, Iran \\ ${ }^{2}$ Iran University of Medical Sciences, Tehran, Iran \\ Email: Nor-alatifi@yahoo.com, ${ }^{*}$ Karimihamid11@gmail.com, Nor-alatifi@yahoo.com
}

Received 4 October 2014; revised 4 November 2014; accepted 1 December 2014

Academic Editor: Vahit Ozmen, Istanbul University, Turkey

Copyright (C) 2014 by authors and Scientific Research Publishing Inc.

This work is licensed under the Creative Commons Attribution International License (CC BY).

http://creativecommons.org/licenses/by/4.0/

c) (i) Open Access

\begin{abstract}
Background: Zygomatic fracture is one of the most prevalent one among facial fractures caused by vehicle accident, motorcycle accident, fighting, fall and sport injuries. Materials \& Methods: This study was a retrospective study of our patients during past 6 years. Results: We had 1277 facial fractures, of whom 9 patients had blindness. We had 193 patients with Zygomatic fracture. 98 patients had pure zygomatic fracture and other had complicated fractures. Frequency of blindness due to zygomatic fracture in a period of six years was $4.7 \%$ in all and in pure zygomatic fractures was $\mathbf{2 . 0 4 \%}$. Blindness was most prevalent in age group 20 - 29 years old (55.6\%). The most prevalent cause of zygomatic fracture which causes blindness, was motor vehicle accident $(\mathbf{7 7 . 8 \% )}$. Blindness was more common in males (77.8\%) than females $(22.2 \%)$. Discussion and Conclusions: One of the most disastrous complication of zygomatic fracture is transection of optic nerve. Very careful examination of fractured bones careful examination of optic nerve and visual acuity and urgent operation and decompression of optic nerve must be performed. About $4 \%-5 \%$ will have blindness purely due to fracture.
\end{abstract}

\section{Keywords}

Zygoma, Zygomatic Fracture, Blindness, Orbit, Optic Nerve

\section{Introduction and Background}

Zygoma is a four quadrant bone, which is located in middle part of face. And because of its prominent and pro-

${ }^{*}$ Corresponding author. 
jected position, it is one of the most prevalent sites of fracture in face, maybe the most prevalent after nasal bone fracture in the face. Etiology of zygomatic fracture are automobile accident, motorcycle accident, fighting or fist fighting, fall, high velocity bullet, sport trauma, etc. [1] [2].

Zygoma is one of orbital bones and is occupied major part of lateral and inferior wall of orbit. It has intimate articulation or adhesion to greater wing of sphenoid in posterior part of lateral wall and to maxilla in the floor of orbit.

Any trauma and force which has enough strength to induce fracture in other bones in posterior third of orbit or enough dislocation of bones, can traumatize optic nerve or even disrupt or transect the optic nerve [3]-[5].

This condition is rare and requires precise and careful examination.

More commonly, blindness may be due to complications of fracture such as intra-orbital hematoma or increased pressure, edema in optic canal, osteitis in fracture site that capture optic nerve, and subdural hematoma posterior to orbit [6]-[10].

In the present study, we retrospectively survey and examined all of patient with zygomatic fracture who were admitted in our hospital in the past six years.

\section{Materials \& Methods}

This is a cross-sectional study in Hazrat Fatemeh Hospital-Tehran (a referral center for maxillofacial surgery and fractures). In this study we retrospectively surveyed all of patients who were admitted due to facial bone fractures and those patients who had zygomatic fracture were included in study.

A special questionnaire was designed and recorded for each patient. Demographic data, etiology of trauma, sex, age, type of fractures (pure or not pure) and fractures of other facial bones, signs and symptoms, type of operation, outcome of patients, cause of blindness, radiographic studies, skull X-rays, and CT scan (if available), were obtained from hospital files and interview with patients.

Follow up was $2 \pm 0.5$ years.

Data was examined and analyzed with SPSS 16 software.

Results were compared with other center's results and previous studies in our center.

\section{Results}

During this survey, more than 9000 patients were admitted in our center and about 1277 patients were admitted to our hospital in a period of six years due to facial bones fracture and about 213 patients had facial bone fractures per each year.

193 patients were admitted and operated due to zygomatic fracture (Table 1).

$83.9 \%$ was male and $16.1 \%$ female. For all of patients X-rays studies and for some of them CT scan was obtained. Surgical operation was open reduction and rigid fixation in all patients.

In more than $98 \%$ of patients rigid fixation was done with plate and screw and rest of them was fixed with wire. Pure zygomatic fracture was found in 98 patients (49.2\%).

In 95 patients (50.8\%) other facial fractures was also present such as Maxillary, Mandibular and orbital bone fractures. Comminuted pan-facial fractures were found in 26 patients $(13.5 \%)$.

Etiology of malar fracture was vehicle accident $55.4 \%$, fighting $31.6 \%$, fall $8.3 \%$, high velocity bullet $1.6 \%$ and others $3.1 \%$ (Table 2).

Most frequent signs and symptoms of malar fracture were malar depression, periorbital ecchymosis, numbness in territory of inferior orbital nerve, malocclussion and trismus, preiorbital edema and diplopia. Blindness was found in 9 patients (4.7\%). Five in right side, 3 in left side and one was bilateral. Blindness in pure zygomatic fracture group was $2.04 \%$.

Among blinded patients $77.8 \%$ were male and $22.2 \%$ female (Table 3 ).

Zygomatic fracture was more prevalent in age group 21 - 30 years old (38.9\%).

The most frequent cause of fracture in blind group was Motor and vehicle accident (77.8\%).

Right side blindness was slightly more common $55.6 \%$.

We had 9 patients that developed blindness as a complication of zygomatic fracture. Blindness was permanent in all of these patients. It was found that fracture parts of zygoma had cut the optic nerve. One of our patients was a 23-year-old man who had motorcycle accident and had not used the special cascade to reduce the chance of head trauma. He had comminuted fracture of left zygoma which transected the optic nerve. He was 
Table 1. Frequency of facial bone fracture and zygomatic fracture in different years.

\begin{tabular}{cccc}
\hline Year & Facial bone FX & Zygomatic FX & Percent \\
\hline 1 & 230 & 36 & $15.6 \%$ \\
2 & 182 & 30 & $16.4 \%$ \\
3 & 240 & 23 & $9.5 \%$ \\
4 & 206 & 28 & $13.5 \%$ \\
5 & 238 & 40 & $16.8 \%$ \\
6 & 181 & 36 & $19.8 \%$ \\
Total & 1277 & 193 & $15.1 \%$ \\
\hline
\end{tabular}

Table 2. Cause of zygomatic fractures.

\begin{tabular}{cc}
\hline Cause & Percentage \\
\hline Car accident & $55.4 \%$ \\
Fighting & $31.6 \%$ \\
Fall & $8.3 \%$ \\
High velocity Bullet & $1.6 \%$ \\
Others & $3.1 \%$ \\
Total & $100 \%$ \\
\hline
\end{tabular}

Table 3. Sex distribution among blinded patients.

\begin{tabular}{ccc}
\hline Side of blindness & Numbers & Percentage \\
\hline Male & 7 & $77.8 \%$ \\
Female & 2 & $22.2 \%$ \\
Total & 9 & $100 \%$ \\
\hline
\end{tabular}

brought to our hospital after 9 hours. In examination no light perception was seen in his left eye. He had left zygomatic frature and lower orbital rim fracture, zygomatico-frontal fracture, maxillary sinus anterior wall fracture, upper central alveolar fracture and left parasymphyseal fracture of mandible.

All of fracture parts were reduced and open reduction and rigid fixation was done for him with \#2 plate and screws, he had complete healing after 5 weeks and he was discharged from hospital after 40 days but unfortunately after 6 months no improvement was noted in visual acuity of left eye and he was considered blind in left eye. He was followed for 2 years and no complication was noted regarding the fracture bones.

Other patients had somehow similar history and in most of them car accident was the primary cause.

\section{Discussion}

Zygoma has a major role in skeleton of orbit. It builds lateral and inferior orbital wall.

On the other hand, zygoma has a prominent position and would be traumatized in most of facial traumas and fractures. It has some absorption effect for the great forces that hit the face. But in doing this role, zygoma may transfer some of the force to its posterior part and hence to the orbit [3]-[5].

Other bones of orbit may fracture in addition to zygoma fracture. Cumulative effects of these multiple fractures could have some adverse effect to orbital content and specially and more importantly, optic nerve. One of the disastrous complications of zygomatic fracture or its neglected side effects is blindness [2] [3] [5] [6] [9] [11]-[13]. 
Sometimes optic nerve disruption is accompanied with transection of third fourth and sixth cranial nerves and it is called "orbital apex syndrome" [12] [14].

Anyhow, there are some rare situations that optic nerve may be transected alone [13] [15] [16]. It is in this situation that blindness may go unrecognized, especially if patient is comatose and surgeon may not notice its presence.

In this study we tried to take attention of maxillofacial surgeons to examined patients thoroughly and provide some information about its prevalence and associated sign and symptoms.

Blindness after facial fracture has been reported to occur with an incidence that ranges between $0.6 \%$ and $3 \%$ [5] [15]-[27]. Vision loss is more frequently in Le Fort III fractures (2.2\%), followed distantly by Le Fort II fractures $(0.64 \%)$ and zygomatic fractures $(0.45 \%)$ [5].

In another study, Kallela et al. reported 10 patients who had blindness after trauma, 4 of them had zygomatic fracture and 6 had Le Fort fractures [9].

Injuries of this type require immediate and prompt consultation by the ophthalmologist. Since blindness is a rare complication of surgical intervention, always the patient ocular status should be evaluated before, during, and after orbital and facial fracture surgery.

Among these patients cause of blindness maybe transection of nerve with sharp bone particles or sometimes due to compression of optic nerve in optic canal by bony fragments or increase intra ocular or intra orbital pressure [2] [9] [13] [19]. In some papers blindness was reported as a complication after secondary reconstruction for zygomatic fracture and most frequently due to displaced bone graft [18].

Retrobulbar hematoma has also been mentioned as a cause of blindness after orbital trauma (less than 1\%) or after reduction of fracture parts [8] [10] [19] [20]. Orbital Subperiosteal Abscess (SPA) complicating zygomatic fracture may result in blindness and CT scan has a high value in determining the abscess [24]. There is some very rare situation that traumatic aneurysm of cavernous sinus was resulted in blindness [20].

Purtscher's retinopathy is another cause of blindness after malar trauma [24] [25].

A displaced orbital bone can cause deviation and eccentric position of gaze and results in blindness (gazeevoked blindness) which is recoverable [26].

In this study we tried to take attention of maxillofacial surgeons to examined patients thoroughly and provide some information about its prevalence and associated sign and symptoms.

Our first patient was a 23-year-old male who had left zygomatic fracture due to motorcycle accident. His blindness after trauma was our motivation to survey cases of blindness due to zygomatic fracture.

During this survey, more than 9000 patients were admitted in our center and among them 1277 had facial fractures that were included in our study.

193 patients had zygomatic fractures (15.1\%). In another study ten years ago in our hospital, prevalence of zygomatic fractures was $16.3 \%$ [28]-[30].

In a study in Osaka, 1051 patients were admitted due to facial fracture and 167 had malar fractiure (15.9\%) [31] [32].

Zygomatic fractures were most prevalent in age group 21 - 30 years old. And there is an increase in frequency of fracture in age group 31 - 40 years old which was $17.5 \%$ in 1993 and $25 \%$ in 1994 and in our study it was $31.1 \%$.

In a previous report in our country, during the period of 1981-1993 there was an incidence of $23 \%$ of malar fracture due to high velocity bullets and objects which was attributed to the war between Iran and Iraq. But now it has a frequency of $1.6 \%$.

Blindness was slightly more common in right side $55.6 \%$ and most frequent cause of it was motor and vehicle accident.

There was no deference in blindness in pure or non-pure zygomatic fracture. One patient unfortunately had bilateral blindness due to severe pan facial fracture.

Blindness was more prevalent in age between $21-30$ years and more prevalent in males. One explanation may be that young male drivers are at high risk of accidents and they should be trained for driving cautiously and using prevention facilities such as seat belt and head cascade. Some special rules for preventing these high speed accidents and using seat belts and air bags in cars are needed. Rescue teams nurses and physicians should be trained again for signs and symptoms of facial and malar fractures and special training course for it should be designed and conducted for medical staff and correct transfer procedure for EMS staff in order to reduce the intransfer trauma to the facial organs and orbit. In this way, we may reduce the prevalence of blindness due to zygomatic fracture in our country [33] [34]. 


\section{Conclusion}

It seems that although a rare complication, blindness and loss of vision is a very important and disasterous situation that surgeons must be aware of it and good physical examination and $\mathrm{Ct}$ scan have a great value in detecting its presence. The most prevalent cause of blindness was vehicle and motorcycle accident (as in other part of world), so more strict laws for prevention of these accidents should be planned.

\section{References}

[1] Patel, B.C. and Hoffmann, J. (1998) Management of Complex Orbital Fractures. Facial Plastic Surgery, 14, 83-104. http://dx.doi.org/10.1055/s-0028-1085305

[2] Gonzalea, M.G., Santos-Oller, J.M., De Vincente-Rodriguez, J.C., et al. (1990) Optic Nerve Blindness Following a Malar Fracture. Journal of Cranio-Maxillofacial Surgery, 18, 319-321. http://dx.doi.org/10.1016/S1010-5182(05)80540-2

[3] Ashar, A., Kovacs, A., Khan, S., et al. (1998) Blindness Associated with Midfacial Fractures. Journal of Oral and Maxillofacial Surgery, 56, 1146-1150. http://dx.doi.org/10.1016/S0278-2391(98)90757-1

[4] Marin, P.C., Love, T., Carpenter, R., et al. (1998) Complications of Orbital Reconstruction: Misplacement of Bone Grafts within the Intramuscular Cone. Plastic and Reconstructive Surgery, 101, 1323-1327. http://dx.doi.org/10.1097/00006534-199804010-00025

[5] Zachariades, N., Papavassiliou, D. and Christopoulos, P. (1996) Blindness after Facial Trauma. Oral Surgery, Oral Medicine, Oral Pathology, Oral Radiology, and Endodontics, 81, 34-37. http://dx.doi.org/10.1016/S1079-2104(96)80144-2

[6] Li, K.K., Caradonna, D., Lauretano, A.M., et al. (1997) Delayed Blindness after Facial Fracture Repair. Otolaryngology-Head and Neck Surgery, 116, 251-253.

[7] Forrest, C.R., Khairallah, E. and Kuzon Jr., W.M. (1999) Intraocular and Intraorbital Compartment Pressure Changes Following Orbital Bone Grafting: A Cilinical and Laboratory Study. Plastic and Reconstructive Surgery, 104, 48-54. http://dx.doi.org/10.1097/00006534-199907000-00007

[8] Hislop, W.S. and Dutton, G.N. (1994) Retrobulbar Haemorrhage: Can Blindness Be Prevented? Injury, 25, 663-665. http://dx.doi.org/10.1016/0020-1383(94)90009-4

[9] Kallela, I., Hyrkas, T., Paukku, P., et al. (1994) Blindness after Maxillofacial Blunt Trauma. Evaluation of Candidates for Optic Nerve Decompression Surgery. Journal of Cranio-Maxillofacial Surgery, 22, 220-225. http://dx.doi.org/10.1016/S1010-5182(05)80561-X

[10] Gray, P.B., Leen, M.M. and Loftus, M.J. (1993) Late Retrobulbar Hemorrhage and Blindness Following Malar Fracture Complicated by Factor XI Deficiency. Journal of Cranio-Maxillofacial Surgery, 51, 669-702.

[11] Ravindranathan, N., Yeo, J.F. and Loh, F.C. (1989) Traumatic Blindness Following a Malar Fracture. British Journal of Oral and Maxillofacial Surgery, 27, 301-305. http://dx.doi.org/10.1016/0266-4356(89)90042-9

[12] Bernard, A. and Sadowsky, D. (1986) Monocular Blindness Secondary to a Non-Displaced Malar Fracture. International Journal of Oral and Maxillofacial Surgery, 15, 206-208. http://dx.doi.org/10.1016/S0300-9785(86)80143-0

[13] Wood, G.D. (1986) Blindness Following Fracture of the Zygomatic Bone. British Journal of Oral and Maxillofacial Surgery, 24, 12-16. http://dx.doi.org/10.1016/0266-4356(86)90033-1

[14] Zachariades, N., Vairaktaris, E., Papavassiliou, D., Triantafyllou, D. and Mezitis, M. (1987) Orbital Apex Syndrome. International Journal of Oral and Maxillofacial Surgery, 16, 352-354. http://dx.doi.org/10.1016/S0901-5027(87)80158-3

[15] Septa, D., Newaskar, V.P., Agrawal, D. and Tibra, S. (2014) Etiology, Incidence and Patterns of Mid-Face Fractures and Associated Ocular Injuries. Journal of Maxillofacial and Oral Surgery, 13, 115-119. http://dx.doi.org/10.1007/s12663-012-0452-9

[16] Magarakis, M., Mundinger, G.S., Kelamis, J.A., Dorafshar, A.H., Bojovic, B. and Rodriguez, E.D. (2012) Ocular Injury, Visual Impairment, and Blindness Associated with Facial Fractures: A Systematic Literature Review. Plastic and Reconstructive Surgery, 129, 227-233. http://dx.doi.org/10.1097/PRS.0b013e3182362a6d

[17] Lederman, I.R. (1981) Loss of Vision Associated with Surgical Treatment of Fracture. Plastic and Reconstructive Surgery, 68, 94-99. http://dx.doi.org/10.1097/00006534-198107000-00020

[18] Butt, W.D. (1979) Sudden Blindness Following Reduction of a Malar Fracture. Annals of Plastic Surgery, 2, $522-524$. http://dx.doi.org/10.1097/00000637-197906000-00012

[19] Knox, B.E., Gates, G.A. and Berry, S.M. (1990) Optic Nerve Decompression via the Lateral Facial Approach. The Laryngoscope, 100, 458-462. http://dx.doi.org/10.1288/00005537-199005000-00003 
[20] Popat, H., Doyle, P.T. and Davies, S.J. (2007) Blindness Following Retrobulbar Haemorrhage—It Can Be Prevented. British Journal of Oral and Maxillofacial Surgery, 45, 163-164. http://dx.doi.org/10.1016/j.bjoms.2005.06.028

[21] Hammer, B. and Prein, J. (1995) Correction of Post-Traumatic Orbital Deformities: Operative Techniques and Review of 26 Patients. Journal of Cranio-Maxillofacial Surgery, 23, 81-90. http://dx.doi.org/10.1016/S1010-5182(05)80453-6

[22] Dancey, A. (2005) Blindness after Blunt Facial Trauma: Are There Any Clinical Clues to Early Recognition? Journal of Trauma-Injury Infection \& Critical Care, 58, 328-335.

[23] Ansari, M.H. (2005) Blindness after Facial Fractures: A 19-Year Retrospective Study. Journal of Oral and Maxillofacial Surgery, 63, 229-237. http://dx.doi.org/10.1016/j.joms.2004.05.221

[24] Gilhooly, M.G., Falconer, D.T. and Wood, G.A. (1995) Orbital Subperiosteal Abscess and Blindness Complicating a Minimally Displaced Zygomatic Complex Fracture. British Journal of Oral and Maxillofacial Surgery, 33, 185-188. http://dx.doi.org/10.1016/0266-4356(95)90295-3

[25] Lipper, J., Pazkowski, J. and Taub, P.J. (2008) Purtscher's Retinopathy as a Cause of Postoperative Blindness. Plastic and Reconstructive Surgery, 122, 68e-69e. http://dx.doi.org/10.1097/PRS.0b013e31817d5f27

[26] Guest, P.G. and Schnetler, J. (1992) Traumatic Cavernous Carotid Aneurysm Resulting in Blindness. British Journal of Oral and Maxillofacial Surgery, 30, 395-397. http://dx.doi.org/10.1016/0266-4356(92)90209-2

[27] Vaca, E.E., Mundinger, G.S., Kelamis, J.A., Dorafshar, A.H., Christy, M.R., Manson, P.N. and Rodriguez, E.D. (2013) Facial Fractures with Concomitant Open Globe Injury: Mechanisms and Fracture Patterns Associated with Blindness. Plastic and Reconstructive Surgery, 131, 1317-1328. http://dx.doi.org/10.1097/PRS.0b013e31828bd4c2

[28] Murray, D.J. and O'Sullivan, S.T. (2007) Intraocular Pressure Variations during Zygomatic Fracture Reduction and Fixation: A Clinical Study. Plastic and Reconstructive Surgery, 120, 746-752. http://dx.doi.org/10.1097/01.prs.0000270845.82498.3b

[29] Ugboko, V.I., Udoye, C., Olateju, S.O. and Amole, A.O. (2006) Blindness and Visual Impairment from Severe Midface Trauma in Nigerians. International Journal of Oral and Maxillofacial Surgery, 35, 127-131. http://dx.doi.org/10.1016/j.ijom.2005.02.014

[30] Stassen, L.F., Goel, R. and Moos, K.F. (1989) Purtscher's Retinopathy: An Unusual Association with a Complicated Malar Fracture. British Journal of Oral and Maxillofacial Surgery, 27, 296-300.

[31] Hampton, G.R. and Krohel, G.B. (1983) Gaze-Evoked Blindness. Annals of Ophthalmology, 15, 73-76.

[32] Yahyavi, A.A. Survey of 200 Cases of Zygomatic Fractyres in Hazrat Fatemeh Hospital, Tehran. Unpublished.

[33] Muraoka, M., Nakai, Y., Nakagawa, K., et al. (1995) Fifteen-Year Statistics and Observation of Facial Bone Fracture. Osaka City Medical Journal, 41, 49-61.

[34] Bataineh, A.B. (1998) Etiology and Incidence of Maxillofacial Fractures in the North of Jordan. Oral Surgery, Oral Medicine, Oral Pathology, Oral Radiology, and Endodontology, 86, 31-35. http://dx.doi.org/10.1016/S1079-2104(98)90146-9 